\section{Michigan Technological 1 8 8 5 University}

Michigan Technological University Digital Commons @ Michigan Tech

7-1-1966

\title{
Studies of the Moose and Wolves of Isle Royale, 1965-1966
}

Peter A. Jordan

Purdue University

Follow this and additional works at: https://digitalcommons.mtu.edu/wolf-annualreports

\section{Recommended Citation}

Jordan, Peter A., "Studies of the Moose and Wolves of Isle Royale, 1965-1966" (1966). Ecological Studies of Wolves on Isle Royale. 56.

10.37099/mtu.dc.wolf-annualreports/1965-1966 


\section{STUDIES OF THE MOOSE AND WOLVES OF ISLE ROYALE*}

Third Annual Report

$1965-66$

by

Peter A. Jordan, Research Accociate Department of Forestry and Conservation Purdue University

Lafayette, Indiana

July 1966

*Receiving principal support during the current year from the National Science Foundation (G-23558), the National Park Service, and the National Geographic Society. .

Not For Publication 
This is the final report on a three-year investigation into the ecology and dynamics of the mooce of Iole Royale National Park. The annual report of 1964 gave a brief recounting of previous researches on the island by Purdue Univeroity personnel. Headed by Durward L. Allen, the long-term program has included L. D. Mech's study of volves completed in 1962 and P. S. Shelton's otudy of beavers completed in 1963. Shelton cubmitted his thesis in Harch of this year, and Hech's vork has just been released as National Park Fauna Series number 7 . Wy field work is completed, and I will be uriting up results this summer: Vendel J. Johnson has undertaken otudies of small mammals on the island as a doctoral dissertation project. Two undergraduates, supported by the National Science Foundation undergraduate research program, are working with him this cummer. Mr: Johnson is familiax with Isle Royale, having studled amphibians there as part of his master's degree research taken at Michigan State University.

\section{Work Progress in 1965-66}

Schedule of work wac approximately the same during this period as described for 1964-65: May 18 through October 31, 1965 was spent on the loland, as well as three veeks in May and one in June, 1966. During these periods pelletvegetation plots were checked, and some new ones were established. Fleld observations were made to measure sex and age ratios in the moose as well as to record their behavior and food habits: Noose remains vere found and examined, and the bones vere measured. To further determine composition of the moose herd, an aerial survey was made in late October using a Piper Cub piloted by Hilliam J. Martila: During summer 1965 two National Science reoearch undergraduate otudento, Erik Stauber and Villiam Seitz-m both with us in previous summers, devoted much of their time to cearching for wolf dens or signs of pupo. In Auguat, Seitz continued the trapping and tagging of beavers, as he had the year before, in order to maintain continuity of records from certain colonies studied. previously by Shelton.

The winter study schedule was the same as in past years. We arrived on the island February 2, 1966, and departed March 24. Dr. Allen was precent for the first four weeks. Objectives were, as in the past, to make close and continuous observations of the wolves, to locate and examine moose killed by the wolves, and to ectimate the total numbers of moose and wolves. Host of our vinter work is done from the air. Our capable pilot and observer Donald E: Murray was, for the eighth winter, a part of the study team. This winter Murray used two different ski-equipped planec: first his Aeronca Champion then later his Piper Super Cub. Agcisting for variouc periodo were the following National Park personnel:

Richard Igo, Hilliam Dunmire, David Kangas, and Jon Abrams. He are especially indebted to Igo for his arduous work in repairing the power lines which were found broken when we arrived on the 1sland.

Weather during this winter, as in many past, was unusual. Then we arrived, snow was deeper than normal for that time, averaging over 3 feet in the woodo. During the month of February virtually none fell. Periods of extreme cold alternated with thawe. It rained twice while we were on the island. The snov surface was unusually poor for tracking. In March we experienced two severe onow stormo, one of which curtailed flying for four days. A1so in March, surfaces of lakes and harbors became sluahy, a condition which impedes take-off of aki planes: It was most fortunate that Murray had switched to the more powerful Super Cub, because operations would have been severely curtalled otherwise. The extent of ice around the icland was oomewhat less than usual, because otrong winds regularly broke it up. 
An interesting effect of weather was the widespread breakage of trees and shrubs: In early November heavy vinds uprooted many conifers: Hore damage resulted after trees and shrubs became laden with 1ce sometime in early vinter. This led to many conifers being snapped off either near the ground or toward their tops. Shrubs, especlally alder, vere broken or bent with tops anchored to the ground: It appeared that 5 to 10 percent of all mature conifero had been topped, with black spruce moot severely affected and white cedar least affected.

\section{The Moose}

This study has been concerned viti population d jarnics, patinology, habitat relationships, and behavior of tive noose. Particular attention is being siven to the characteristics of those moose killed by wolves.

\section{Lumbers of moose}

In the 1965 report a method of counting moose from the air on a series of small plots was described, With certain refinements, this was used again in 1966. The moose on Isle Royale are not uniformly distributed in winter. Hence, to increase sampling efficiency, the icland ras divided into four strata of thoose density, and each stratum was sampled as a unit. This program was designed in conjunction with our departmental statistician, Peter E. Dress.

Criteria for celecting strata were based on records from past winters plus observations this winter made during the first week of flyinc. The number of plots in eacin stratum was assigned in proportion to its ectimated number of moace. The intelal sample consisted of 40 plots. As in 1965 , plots ranged in size from 0.2 to 0.7 square mile. After the first 40 had been counted, results were analyzed to determine sampling error (variance) in each stratum. Numbers of plots added thereafter were assigned in proportion to magnitude of sampling error in each otratum. In this manner, samplinc effort could be applied more in accordance with the distribution of moose than if a single random sampling had been made. A total of 63 plots were counted. Because time avallable for counting was 1 imited by unusual weather and poor tracking, this total was less than had been hoped for. The 60 included the initial 40 plote plus one serfes added after malking variance calculations.

Contrary to expectations, the stratified sampling system did not produce a lower samplinf error than that of 1965. Error was greater despite the fact that nearly twice as many moose were counted, there vere nine more plots, and the total area counted was increased from 8.6 to 12.1 percent of the island. This greater error must have resulted fron the unusual degree of agsregation shown by the moose this winter. For example, counts from three plots shoved densitles of more than 40 per square mile. When epatial distributions are clumped, a greater sampling effort is required to maintain a given level of accuracy. Despite the overall decrease in accuracy, it could be shorn statistically that stratification had improved ampling efficiency. The following table shows results of the stratified count. 


\begin{tabular}{|c|c|c|c|c|c|c|}
\hline Stratum & Plots & $\begin{array}{r}\text { Total Area } \\
\text { (sq: mil) } \\
\end{array}$ & $\begin{array}{r}\text { \%Area covered } \\
\text { by plots } \\
\end{array}$ & $\begin{array}{l}\text { Moose } \\
\text { counted }\end{array}$ & $\begin{array}{l}\text { Moose per } \\
\text { sq. mi. }\end{array}$ & $\begin{array}{c}\text { Eotimated } \\
\text { total } \\
\end{array}$ \\
\hline $\begin{array}{l}1 \\
2 \\
3 \\
4\end{array}$ & $\begin{array}{r}7 \\
13 \\
23 \\
25\end{array}$ & $\begin{array}{l}58.50 \\
67: 50 \\
59: 00 \\
30: 50\end{array}$ & $\begin{array}{r}5 \\
10 \\
14 \\
20\end{array}$ & $\begin{array}{r}1 \\
11 \\
31 \\
100\end{array}$ & $\begin{array}{r}0.56 \\
1.67 \\
3.86 \\
11.81\end{array}$ & $\begin{array}{r}20 \\
113 \\
228 \\
360\end{array}$ \\
\hline $\begin{array}{l}\text { The } \\
\text { Island }\end{array}$ & 68 & 212.75 & $12: 1$ & 143 & 3.34 & 721 \\
\hline
\end{tabular}

A population estimate of 721 moose was obtained: At the 95 percent confidence level, it can be said the population is somewhere between 593 and 948: This estimate is not significantly different from the 847 calculated for 1965. Actually a drop in total number was expected because the calf crop this year was below nomal, and the number of calves surviving their first winter last year vas below normal; removal of adults presumably continued at the ucual rate.

All inaccuracies in counting lead to underestimation. If the sampling procedure is valid, then the estimate must be considered conservative, and in vinter 1966 poor counting conditions probably magnified this. On a basis of the number of times a moose was nearly missed in counting, it is est imated that between 10 and 25 percent of all animals on the plots were not seen. Consequently, the moose population last winter probably was between 800 and 900 . The year before it was estimated at between 850 and 1,000 .

Weather and cover on Iole Royale have always been an impediment to counting moose from the air. This winter an improvement was inadvertently discovered when, half way through the study period, our pilot owitched planes as mentioned above. The Super Cup is powered by a $135 \mathrm{hp}$; engine while the Champion has but an $90 \mathrm{hp}$. engine. Although the Champion is slightly more maneuverable, minimum speed is about the same in both. Of significance was the fact that the Cub could be used for counting when winds were as strong as $25 \mathrm{~m} \cdot \mathrm{p} \cdot \mathrm{h}_{\bullet}$, while the champion vas usable only in winds up to $15 \mathrm{~m}: \mathrm{p} \cdot \mathrm{h}$. Because brisk winds were comnon during March, use of the Cub permitted counting 15 to 20 more plots than would have been possible with the other plane:

Because this moose population is isolated, hence not subject to ingress and egress; a total count is quite meaningful; It is necessary for quanitiative analysis of the predator-prey relationship. Age structure as vell as production and replacement rates can be measured with reasonable accuracy; from these the total number of moose being removed by wolves can be calculated as was done by Mech. Continuing efforts to refine the counting technique should be rewarded. However, to increase accuracy significantly over this year's may require new methods or devices such as counting from a helicopter or using an infrared scanner:

\section{Population estimates and distribution according to pellet counts}

Over the past three years 428 permanently marked plots, distributed in 29 widespread sites, have been established for making pellet counts and for recording vegetation trends: Detalls of this were described in the 1965 report: Although all plots were not rechecked for pellets each year, enough have been checked to justify 
a brief summary of reoults. When plots are cleared in the fall and visited the following spring before emergence of ground cover, numbers of pellets deposited during the interval can be measured accurately. Though summertime count 3 of moose droppings vere made, results from this season are not quantitative rellable.

Location of the plots has bot been randomized over the island; hence, the sample is not representative. Neither has the sample been large enough to assure an accurate estimate of pellet density even in those regions which have been sampled. The main purpose of establishing these plots was to relate moose distribution to various vegetation types and to have an: index of long-term population trends. It is, neverthelsss, instructive to see how pellet count resuits compare with the estimate from aerial counts.

Studies elsewhere have provided an estimate that in winter the defecation rate of moose is about 13 groups per day ${ }_{c}$ Using this rate, estimated moose denoities were calculated for each of the locations in which a Iine of plots had been counted for at lease one winter: The results ave an average of $8: 67$ moose per square mile. Thic would extrapolate to over 1,800 for the island-. that is, more than twice the number estimated from the aerial method. We must asoume that the more direct aerial count, though subject to some error, is a far more reliable method.

Sampling may have favored the moxe heavily used portions of the island, but this could not account for the magnitide of the diocrepancy: As a partial check, the total population estimate was recalculated from pellet data according to the ctrata used in the aerial sampling. A density average was determined for each stratum from all plots which happened to lie within it, and these were extended in accordance with the area of each otratum. It turns out that both the most dense and the least dense strata had been undersampled for pellets: Total population estimate, however, was 1,916 or 8.88 per square mile, hence rather close to the first or gross calculation from pellet data: This suggesta that the present distribution of pellet plots is not giving reoults widely different from that expected from the same nusber if distributed at random. Statistical tests have not been run to determine confidence limits, but it appears that the counting of 370 different plote for a three winters' total of 631 replications should not give a figure which is off by a factor of two. The wide discrepancy here must be accounted for in other terms, most probably in the presumed rate of defecation. It is proposed that, rather than 13 groups per day, these moose may have a rate of between 20 and 30 per day.

Efforts to determine the defecation rate by tracking moose for known periods in winter, as described in earlier reports, have not been successful. The time and opportunity to do this has been scant. When individuals were tracked from a given point, their tracks usually intermingled confusingly with those of others before they could be relocated.

Certain distribution patterns can be inferred from the pellet counts. In mony cases local distributions as revealed by fall-spring pellet counts, did not correspond with thoce observed from the air during midwinter: This indicates that in some areas the moose shift about considerably from month to month as had been suspected: Some of the heavy concentrations seen in winter probably are quite temporary; There was evidence that occupancy of some sites is consistent from 
year to year, while in others it is highly inconsistent: For example, as a result of the extensive topping of balsam fir last winter, a great amount of preferred forage was made available to the moose, thus leading to local concentrations at unusual sites:

Productivity in the inoose

In 1964 an exceptionally large calf crop was produced: However, these were reduced so severely that by late fall the percentage they comprised of the population was below normal: After that, survival was good through to the follwoing summer: This finding was based on both winter counts and on the number of yearlings found in the summer of 1965. At the same time, some animals around the age of one year were being taken by wolves: remains of three were found in summer 1965:

Calf production during the next summer, 1965, was well below normal: Fragmentary counts indicated that around 49 per 100 adult females were present in midsummer: At that time 23 percent of 38 cows seen with calves had twins; this may be compared to the 1965 figure of 48 percent: Another index of production and loss is the number of calves found dead in summer. The probability of finding or hearing about dead calves in 1965 was the same as in 1964. Two were found in summer 1965 compared to six in 1964: Aerial survey in late October, combined with ground observations that month, showed 21 calves per 100 adult cows. The incidence of twins had dropped to 7 percent: At this time calves comprised 9 percent of the total in a sample of 164 moose observed:

Aerial classification during winter 1966 showed that calves still comprised 9 percent of the herd, based on a sample of 143. There were no twins among those classified, although one set was seen during nonsystematic observations: Another set of twins was observed in May 1966. Two calves killed in March may well have been twins. If the fall adult sample of 85 adult bulls to 100 adult cows is taken as representative, these findings indicate that survival of calves from fall through winter was as high as survival in adults. Among moose killed by wolves in winter 1966, and for which age has been determined, 4 of 20 (20 percent) were calves; these included the aforementioned two which were assumed to be twins: Under existing circumstances, the probability of finding calves killed by wolves was somewhat lower than for finding adult kills.

It was suggested in last year's report that unusually stormy weather may have disrupted breeding in fall 1965. This was suggestively born out by the poor crop which followed, but there is no direct evidence on which to base such a conclusion: In fall 1965 weather was normal, ijeo, intermediate between the stormy fall of 1964 and the unusually mild season of 1963: The follwoing table shows the percentages of adult males in the company of adult females, and vice versa, during the fourth week of October. This is near the end of the rutting season, and presumably the amount of male-female association would indicate the extent to which cows had not yet been bred: Furthermore, extremes of weather may actually impede breeding success. 


\begin{tabular}{|c|c|c|c|c|}
\hline \multirow[b]{2}{*}{ Year } & \multicolumn{3}{|c|}{$-6-$} & \multirow[b]{2}{*}{$\begin{array}{l}\text { Calf Crop } \\
\text { the following } \\
\text { Summer }\end{array}$} \\
\hline & $\begin{array}{c}\text { Fa11 } \\
\text { Weather }\end{array}$ & $\begin{array}{l}\text { Adult Cows } \\
\text { Accompanied } \\
\text { by Adult Bulls }\end{array}$ & $\begin{array}{l}\text { Adult Bulls } \\
\text { Accompanied } \\
\text { by Adult Cows }\end{array}$ & \\
\hline $\begin{array}{l}1963 \\
1964 \\
1965\end{array}$ & $\begin{array}{l}\text { mild } \\
\text { stormy } \\
\text { normal }\end{array}$ & $\begin{array}{l}23 \% \\
42 \% \\
32 \%\end{array}$ & $\begin{array}{l}28 \% \\
56 \% \\
40 \%\end{array}$ & $\begin{array}{l}\text { high } \\
\text { low } \\
\text { tit }\end{array}$ \\
\hline
\end{tabular}

to: During the first week of June, 1966, among a small number of moose seen, three single calves were observed: By mid-June there were several reports of dead calves. These early observations probably indicate normal or high production this year.

The data permit no more than speculation. To show a real relationship would require years of such records. In areas where female moose are hunted, the question could be explored by ovarian analyses: that is, fertilization rates from year to year could be compared on the basis of autumn veather.

\section{Mortality Patterns}

During the winter of 1966, 21 moose carcasses were accounted for, and, of 16 known adults, sex was determined for 19 and age estimated for 14 . Only two were males: One, a prime-age bull, had suff red a multiple compound fracture of the left tibia some time before: The bone had mended but was still badly deformed, and no doubt the animal was easy prey for the four wolves found eating its remains. Among adults killed during a single winter, the sex ratio this year was more uneven than in any previous year. In 1965 there were 7 males and 10 females, and in 1964 there were 5 males and 9 females: Fall counts in the field indicated that adult females currently outnumbered adult males 100 to 85 . In the past, however, males have predominated both in fall counts and in total numbers of those adult carcasces which represent deaths in all seasons: In any event there must be a significant increase in vulnerability of females during midwinter. Factors possibly responsible include a lower mobility of females in deep snow due to smaller body size or some effect of pregnancy on overall strength. Actually, there is no good basis even for theorizing on this point.

The other bull found killed this winter was quite old. Among the 10 females, there were two yearlings, one young adult-- probably around 4 years, two middle age-- probably 5 to 8 years, and the rest were older. Among 31 adults examined in 1964 and 1965 there were 3 yearlings and 1 young adult: thile the four young animals from the previous two years were all male, the three young individuals this year were female. It is notable that, while in the previous winters the young animals had all been taken by the large pack, this year all were taken by lesser wolf groups-- the pack of four and at least one by just two wolves. In general, the downward trend in age of animals being removed during winter doubtless reflets a corresponding decline in average age within the adult population. The relationship between age and vulnerability as previously indicated in these studies probably is changing and needs continuing reappraisal:

Determining age from tooth annulations is now in progress: John $\mathrm{C}$ : Olson, graduate in Forestry and Conservation, is decalcifying, sectioning and examining teeth from our extensive collection of specimens acquired over the past 8 years. From these results, more precise analysis of population trends should be possible: 
A publication on the bone diseases of Isle Royale moose is being prepared in cooperation with E: 0 : Haeltermann and G. M. Neher of the Purdue School of Veterinary Science and Mediclne

In cooperation with the Minnesota Department of Conservation, a survey has been made to determine the incidence of "moose disease", Pneumostronglyus tenuis, in Isle Royale moose. Patrick Karns and his colleagues in Minnesota have examined 94 samples of moose feces collected on the island, and they have discovered two single eggs of the parasite. Neither of these was in a sample taken from a wolfkilled moose: Ordinarily dramatic outbreaks of moose disease occur where whitetailed deer are abundant, because, as revealed by the work in Minnesota, deer probably act as a reservoir of contagion: Finding a very low level of Pneumostronglyus on deer-free Isle Royale is of particular value in light of the Minnesota discoveries. No record exists of an Isle Royale moose succumbing to this parasite: The behavioral symptoms during the terminal stages of this disease are apparent enough so tinat any person encountering such an animal would readily notice its peculiar movements and lack of wariness:

\section{The Wolves}

Although studies of the past three years have been directed primarily toward the ecology of moose, they also afforded the opportunity to make important observations on numbers, behavior, and social structure in the wolves. In keeping with original study objectives, there has been continuing effort to census the wolves and to understand their predatory habits. A summary of wolf observations during the interval since Mech completed his studies is now being prepared for presentation and subsequent publication in a symposium (August, 1966) at the meetings of the American Institute of Biological Sciences:

After three winters, I believe that I can recognize a few individual wolves from the airplane: Small groups can be distinguished with fair surity on the basis of combined characteristics in several animals. This has aided in the counting of wolves. Recognition of the lead wolf in the large pack has, as described in the 1965 report, underlain important interpretations of social behavior:

Numbers, pack structure, and reproduction

The best estimate of Isle Royale's wolf population for the winter of 1965-66 is 25 , less 2 known to be dead. The large pack was observed once in early February to comprise 15 animals; thereafter no more than 11 or 12 were seen together. Of these, 9 traveled closely, 2 often stayed far back, and the 12 th joined only occasionally. Among the 9 was the lead or alpha male, discussed in last year's report. This animal evidently died during the period of winter study (see below). There were, in addition, two separate groups of two wolves, a group of four, and one or more singles. The other animal known to be dead was a pup which probably had been with the four and which apparently died before our arrival in early February. Since a good single count of the island was never possible; the population estimate of 25 $(-2)$ had to be arrived at indirectly using such evidence as incidence and distribution of moose kills, fresh tracks, and group recognition.

In 1965 a "new" pack of five animals including a pup and a breeding pair was observed at the northeast end of the island. Occupying the same region in winter 1966 was a pack of four: This did not contain a breeding pair; three appeared similar in size and coloration, with the fourth being smaller. The small one 
behaved somewhat pup-like according to our rough and untested criteria: The similarity of locale strongly suggests that this group comprised the same individuals found thereabouts in 1965: The large male seen breeding and observed to be leading in 1965 was no longer present-- possibly a casualty.. In spring, 1966, the scattered remains of an immature wolf, estimated to have been between 5 and 8 months of age, were found in the area frequented by these wolves. It is supposed this animal was a product of the breeding pair seen in 1965 .

Except the suspected pup observed and the one found dead, no. Indication of pups was uncovered last winter. The survey conducted by two undergraduate students for 10 weeks in midsummer,' 1965 to locate dens or signs of pups produced no evidence of young being raised. Such evidence had been discovered the previous summer: According to Stanley Sievertson, commercial fisherman, on July 18, 1965 a group of at least 12 wolves were together on Rainbow Cove. This doubtless was the majority of the large pack. Their being together suggests that pup raising was not then in progress on the southwest end of the island.

During winter 1966 there were within the big pack two actively breeding pairs at the peak of the breeding season. Shortly before, the lead male had been actively courting a female; however, he subsequently became lame and had difficulty keeping up with the others (see below). Because of the pack's reduced size and changes in its social structure (see below), it is anticipated that pups will be raised successfully this current season. This prediction is further supported by the food supply outlook: as mentioned above it now appears that a normal or above normal calf crop was produced this season: Furthermore, an unusually high incidence of beaver remains in wolf droppings this spring indicates that beaver availability is favorable:

During March a wolf digging was sighted from the air near Todd Harbor. It was on a steep south slope where snow cover was neglibible. We visited the site in mid May, and found a large den freshly dug out. However, there was no sign of current occupancy nor of any pups being reared there this spring. Another check in early June again showed no activity. When the den was spotted last winter, two wolves were moving together in the vicinity. Presumably these were responsible, although nothing could be determined about their sex or breeding status: That the wolves dug this out before snow melt suggests it was an old den. Aierial searches were made over other likely areas during May, particularly in the region of the big pack: Although shallow diggings by wolves were seen in several places, no other den was found: The afrcraft employed in May, a Cessena 180, was considerably faster and less maneuverable than the planes we regularly use; hence we were not able to search as carefully as usual.

Soclal relationships in the large pack

As reported last year, striking changes had been observed between 1964 and 1965 in in certain social parameters of Isle Royale's large wolf pack: These, it was. postulated, might have been associated with a change in the role or attitude of the lead or alpha male: Although conditions favoring careful behavioral observations were not good in 1966, it was possible to record further distinct changes: The pack had fewer members, and its travel pattern was different. Incidence of greeting, play, and harassment of subordinate individuals was greater than in 1965 but less than in 1964. Some types of interactions differed as compared with the two winters before: One severe fight was witnessed but the particlpants could not be identified. 
Until March, the alpha male appeared to behave approximately as it had in winter 1965: The other members continued to respond toward hin as before, but he did not seem to press his role as dominant male: Ordinarily he did not directly lead the pack in its travels: An exception to this was observed on the 20th of February when he was actively following a female: There did not arise an opportunity to determine whether the alpha male was interfering with breeding efforts of other pack members until, as described below, after he was physically impaired.

On February 24, as the pack traveled, it was divided into two groups more than a mile apart: Both subgroups were led by a female who in turn was being pursued by a male: The alpha male was trailing behind the first of these groups, and he appeared to be limping markedly. It had already been observed that, on February 20, he had a slight 1imp. The next day, 10 miles away, as the pack traveled in the same sort of pattern, the alpha male showed an even more pronounced 1 imp: It was severe enough so that, as the others were walking rapidly, he had to lope to keep up: The pack was not seen from February 26 to March 12 when eight animals were resting and socializing together on Feldtmann Lake; The alpha male was not observed to be among them.

During the unaccounted-for interval, the pack killed and ate one calf, then returned some days later to the same site and killed and ate a second calf. At this place we detected from the air the remains of a wolf. These, which were retrieved via a snowshoe trip, included a piece of hide 52 inches long, bones of the hind 1 lmbs, the pelvis, and a few vertebrae One hind foot was 150 yards from the other parts. A thorough search at that time, plus another search after snowmelt in May, failed to turn up a skull or other bones:

All evidence suggests that this animal was the alpha male, and that it was killed and eaten by its pack mates. From the air we had distinguished the alpha male by its more yellow color and its larger size. The remains showed these characteristics in a comparison with those of another wolf, believed to have been a male, picked up in winter, 1964. Radiographic examination of the lower lumbar vertebrae and hind leg bones revealed arthritis which, according to radiologist R. E: Lewis and osteologist G: M. Neher of Purdue's Veterinary School, could have accounted for the onset of lameness: That the animal had died violently was partly evidenced by marks on a fallen balsam fir: Along one part of the tree, limbs of 3/4 inch diameter on the under side showed heavy chewing and breakage-- doubtless from the teeth of a wolf. It is hypothesized that the animal retreated or was forced under the fallen tree and ended up biting wildly at anything in reach. Tufts of. hair lay aroung this site, and some were snagged on the branches: It is quite possible the animal died here. Finally, scattering and disappearance of most of the remains seemed more attributable to wolves than to foxes or ravens;

It is suggested that the dominant male, being somewhat impaired physically, was challenged. Because he was not inclined to back off-- as wolves at a disadvantage usually do, he precipitated a full confrontation-- and lost.

About two weeks after this loss, and quite possibly related to it, the remainder of the pack were seen outside the region in which they had confined themselves during the past four winters. They moved to Lake Theresa, 3 miles farther east than they had been recorded since wintex 1962 and 5 miles farther than since winter 1964. During the winters 1959 through 1962 they had traversed that northeast part of the island regularly, though not predominantly. Perhaps this alteration was in some way related to a change in leadership. 
Patterns of travel and hunting in the large pack

This winter the pattern of hunting and travel in the big pack was different from that in any other year of the study. Although, with the one exception noted above, they confined themselves to the southwest two-thirds of the island, these wolves seldom used the habitual routes of winters past. Their travel, instead of being along shores or between major lakes, was concentrated inland. Often they took random, zigzagging courses: The large pack killed no moose less than 0.7 mile of the lake shore and none at all close to a traditional route. A valid comparison cannot be made with the habits of wolves at the other end of the island. Travel pattern in the pack of four was not nearly as well known, and since their region is dissected by far more harbors and lakes, they were not presented with such a clearcut choice of terrain types. In general, the four traveled crosscountry some, but more along shores and harbors, and their kills were correspondingly distributed:

Movements of the large pack this winter were not related to a change in moose distribution. The inland areas they covered were, as usual, frequented by fewer moose than were the shorelines. The wolves' intensive hunting efforts inland were relatively unproductive. Snow condition was probably the factor underlying so much inland travel. There certainly were periods when walking was easy due to well packed snow surfaces. However, while the inland travel persisted through the seven weeks of our study, surface conditions varied widely. After the big storm in March had dropped 15 inches, the wolves were cutting deep furrows, yet they still remained inland. Thus it is not possible to identify with certainty what factor did prompt the distinct change in travel habit.

Rate and distribution of kills

In past years it has been possible to keep a reasonably accurate account of k11ls made by the large pack during our in winter stay. This year, however, with fewer wolves in the group, poorer tracking conditions, and the pack's more inland travel, the accounting was incomplete. Only seven kills, including two calves, were known to have been madc by the large pack during our stay. One of these was apparently made by a subgroup of three or four wolves. In addition, eight of the pack once fed on the partial remains of an adult cow killed earlier by a separate pair of animals.

Unusual was the fact that eight kills could be attributed to the lesser groups during the same period, including only one calf. In past winters, numbers known to be killed by lesser groups have been half or less those killed by the large pack. There apparently has been some shift from the majority of kills on the island being made by the single, large pack.

It is believed that all kills made by the pack of four were recorded. These included one calf killed about four days before our arrival. In terms of consuaption rate, these moose would have provided 14.2 pounds per wolf per day, according to the calculation figures given in last year's report. This can be compared with the averages of 10.5 and 10.6 obtained for the large pack for winters 1964 and 1965 respectively. 
Outlook for Further Studies

As mentioned previously, this report terminates three years of investigations supported primarily through National Science Foundation Grant G-23558 to Durward L. Allen, as responsible investigator: Supplemental grants were received from the National Park Service, National Geographic Society, and the Wildiife Management Institute.

Another phase of the investigations begins June 1966 under a new two-year grant from the NSF and a renewal of the National Park Service support: Wendel $J$. Johnson is studying the numbers and dynamics of the fox and its food species (i:e.: hare, red squirrel, and woodmouse), and a post-doctoral appointment will be made for continuing the moose-wolf phase of the program. 
STUDIES OF THE MOOSE AND WOLVES OF ISLE ROYALE*

Second Annual Report

$1964-65$

by

Peter A. Jordan, Research Associate Department of Forestry and Conservation Purdue University

Lafayette, Indiana

17 May 1965

* Receiving principal support during the current year from the National Geographic Society Committee for Research and Exploration, the National Park Service, the National Science Foundation (G-23558), and the Wild life Management Institute. 
This report covers principally the second year of a threeyear investigation of the ecology and dynamics of the moose in Isle Royale National park. In the annual report for 1963-64. there was a brief recounting of past work on the island by Purdue University personnel. Headed by $D$. L. Allen, the long-term program has included L. D. Mech's research on wolves, coinpleted in 1962, and $P$. S. Shelton's study of the beaver completed in 1953. In both past and present work inforination on moose, particularly population dynamics and the characteristics of wolikilled individuals, has been collected. Likewise, observations on the woltes have been made with a continuity of approach through the seven years of study. In this year's report in addition to current findings, some longer-terin summaries are given.

\section{Work Progress $1964-65$}

Field work for this report period commenced with three weeks of ground work in May, 1964. On plots laid out the previous Fall, pellets of both moose and hares were counted and cleared. Ground search was made for moose in order to deternine over-winter survival and sex ratio in the calf crop of the previous summer. One moose was autopsied in liay, and, during the many miles of cross-country hiking, a number of remains were discovered and examined. Fragmentary data on wolf activities were also obtained. During the surnmer, observations of moose were continued; more carcasses were examined; new pellet-count plots were laid out and described; and, during the fall, most plots were again counted and cleared. In September and October, Larry Roop, an undergraduate at Purdue was employed as rield assistant. In late October, five days were spent making aerial herd composiiion counts using a Piper Cub piloted by william $J$. Martila of Eveleth, ivinnesota. During summer and fall significant new observations were made on wolf reproduction. Working with us during the summer were two students on the National science Foundation undergraduate research program. Erils stauber, in his second summer on the island, continued his survey of birds of prey, while William seitz trapped and studied beavers in certain of shelton's study colonies. The three of us were able to coordinate our various projects efficiently.

The work schedule in winter 1965 was essentially the same as in past years. We arrived on the island February 2 and departed March 23, with Dr. Allen being present the First four weeks. Winter work consisted principally of following and observing wolves, locating and examining kills, and censusing moose. It was carried out from an Aeronca Champion ski-ecuipped plane operated by our skilled pilot and observer Donald E. Murray who was with the program for his seventh winter. Also participating in the wintex operation were chief naturalist William $W$. Dunmire, radio technician Richard Igo, and ranger Jon B. Abrams. Although we were plagued by an unusual amount of stormy weather. our total flying time of 14.3 hours was not below average for 
past years. Observational contact with the wolves was interrupted several tines for two- and three-day spans. Normal ainounts of ice were present on bays and shores; however the surfaces were unusually rough for landing, and the aircraft sustained certain damage from this.

\section{Nuinbers, Dynamics, and Condition of Moose}

This study is concerned with population dynainics, pathology, habitat relationships and behavior of the inoose. Particular attention is being given to the numbers and health status of moose killed by the wolves.

Production and survival of calves in 1964-65

As was pointed out in the previous report, an estimated minimum ratio of 100 calves per 100 adult cows was found throughout the summer of 1963, indicating a natality sonewhat higher than average arnong moose herds studied elsewhere. In 1964 an even higher birthrate was indicated. Between June 6 and Septernber 29, 75 cows and calves were classified, from which a ratio of 97 calves per 100. cow's was calculated. Yearli.ng cows, according to records from the previous winter and spring, comprised approximately.23 percent of adult females. . When these are excluded, becáuse they are reproductively-inmațure, the ratio' per 100 maturè cows was 129: calves. Since"sample sizes were relatively small, the estimates are only approximate. All factors considered, however, this nataility estimate probably is conservative because counts ranging over a period of three months do not account for early losses, and young calves are proportionally more difficult to observe. Of the 25 cows found with calves, at least 12 (48 percent) had twins: -Some of the remaining singles could have been survivors of original twins. It can safely be stated that 1964 witnessed an unusually large calf crop possibly 25 percent or more. above 1963.

Losses in this large crop were undoubtedly heavy between early summer and mid-autumn. One indication of this was the number of current calf carcasses found during the period. There were six such animals in 196 : 4 as compared to a total of eleven in all the six previous summers combined. One of these six calves was killed by wolves. Reliable reports were received on two additional calf kills, but carcasses were not located. Anong the five nonwolf kills, one may have drowned, one had suffered a compound Eracture of the right metatarsus, another was probably separated from its cow by human disturbance, and in the remaining three no mortality cause could be determined. In the instance of the wolf kill, valuable observations were made by seasonal ranger, $K$. M. Pietila, on a violent battle between the calf's mother and some three to five wolves. 
Aerial herc composition counts in late October showed an estimated 25 calves per 100 cows, or on the same basis as above, 32 calves per 100 mature cows. This indicates that many calves died during the first five months after birth. Though the Figures are somewhat rough, differences of this magnitude leave little doubt that a large proportion were lost.

A suitable explanation for such heavy losses following high natality, including an apparently high non-predatory toll, can not now be suggested. It does not appear that a decline in the welfare of the herd as a whole was involved. Census estinates plus the condition of animals examined in winter, contradict such a supposition. Records of the past seven years.show that Fluctuations in production and survival have been common. If nothing else, it is of interest to know that a noose population subject to continuous, effective predation does demonstrate such variability.

In the late winter period, February-March, calves constituted 10 percent of the total population. Only in 1961, at which tine ijech found 10.5 percent, has the ratio been that low; in the other winters observed ratios were from 17 to 27 percent. In Iate October 1964, calves comprised an estimated 12 percent. Rate of loss in calves during the intervening period thus appears to have been close to that in adults. Percentage incidence of calves in the 1965 winter kill was approximately equivalent to their incidence in the winter population. This constitutes a high survival rate for first winter young. When relatively few calves are present. contacts between calves and wolves are less; hence there are fewer opportunities for killing. The condition of cows may have been such that they were able to defend their calves more effectively than usual. Also heavy losses during sumer and early fall undoubtedly reduced calf pairs disproportionaltely so that cows which had born twins were left with but one calf to defend. From 48 percent in midsummer the incidence of pairs dropped to 12 percent by late october, and no twins at all were seen in the midwinter field work.

Adult mortality

On Isle Royale, wolf predation accounts for a large majority of adult moose losses. However there is great individual variation in vulnerability. These differences largely involve old age and pathology, the two factors being commonly interrelated. From the start of this project, a positive relationship between age and vulnerability has been eviclent. Specific pathological findings and their implications will be discussed under separate heading.

Determining the age of death of wolf-killed adults is a reçuisite for studying vulnerability relationships-- hence .: understanding the dynamics of predation. To date this has been done by relating age to the degree of tooth wear. Though valuable, this technique is not accurate enough for the type of analyses we would like to make. A newer method, promising to provide 
such accuracy, will be undertaken within the coming year. This consists of microscopic examination of tooth roots for annular patterns similar to the annual rings in trees. Then teeth from the 195 adult moose remains now on hand have been analyzed, the age relationships of the entire collection will be reviewed.

In this connection, a point at issue is the appearance of young adults arong the kills by wolves in winter. Prior to 1964 no animals between one and five or six years of age had been accounted for. In 1964 two yearling males were killed, and in 1965 one twoyear-old male and one three- or four-year-old male were killed. These records imply a downward trend in age of vulnerability, but a more reliable analysis will have to await the results of further age determination work. If such a trend is in progress, it inight indicate that very old animals are less numerous than they were a few years ago-- a prolonged adjustment to the advent of predation on this population around 1949 .

From records on moose of accurately determined age, it is expected that a life table for the Isle Royale moose herd can be constructed, giving a comprehensive picture of age distribution and turnover rates. Through March 1965, the following specinens have been collected during the seven years of the program:

I. Carcasses examined and teeth recovered:

a) Accounted for during winter studies:

$$
\begin{aligned}
& \text { Adults. . . . . . } 97 \\
& \text { Calves . . . . . } 32 \\
& \text { total }
\end{aligned}
$$

b) Accounted for at other times:

$$
\begin{aligned}
& \text { Adults • . . . . } 98 \\
& \text { Calves . . . . . } 51 \\
& \text { total }
\end{aligned}
$$

II. Accounted for without recovering teeth or other a,e criteria . . . 16

III. Autopsies (not including animals fatally wounded

$$
\begin{aligned}
& \text { by wolvesl. . } 7 \\
& \text { Total }
\end{aligned}
$$

Numbers of moose

In February and March, 1964, a limited aerial survey of moose was carried out by counting ten sample plots ranging in size from 0.82 to 7.73 square miles. The flight pattern was principally by strips, but on occasion more intensive searches by circling were made. In 1960, Mech had covered the entire island by aerial survey. He counted 529 moose, and from this estimated the population at 600 . A comparison of 1964 results with the number of moose plotted on the same areas by Mech in 1960 gave a figure 17 percent higher for 1964. However, lack of statistical treatment prevented any firm conclusion on population trend. 
A more systematic sampling method was designed for 1965. Experience in counting during 1964 showed that, to obtain an acceptable level of accuracy, aerial searching had to be as intensive as possible. Not only was the strip method found inadequate, but even when all moose tracks seen along the strips were traced out, many animals could be missed. It was concluded that every piece of ground should be viewed several times from different directions. To accomplish this a flight pattern was employed wherein strips were covered with a circling course which allowed for ample overlap. Degree of overlap was increased with increasing density of cover and increasing numbers of fresh tracks. Since coverage of the entire island using this technique would have been impossible, the sampling was designed to cover a series of plots. The size of these was kept small, 0.25 to 0.50 square miles, for two reasons. Time to cover a plot should not exceed 20 minutes, because in continuous searching the observer's efficiency begins to drop with longer periods. And on larger plots this flight pattern gives rise to errors from the inability of the observer to keep track of sectors already covered. This is particularly true if the animals are moving. In most instances 700 feet was found to be a good flight altitude, though this was varied according to the situation.

The following environmental conditions were found to influence success in counting: First, when winds were greater than 15 iniles per hour, it was found inadvisable to make counts. With lesser winds, only plots along the windward shore were counted, because, as wind moves across the island's ridges, it creates turbulence above. The quality of snow surface was found to be critical. Animals were most easily spotted during the first day or two following a new snow of at least two inches. This was rela ted both to tracking and the ease of spotting animals against the texture of new snow. Less critical, but important, were quantity and quality of light for counting. A high intensity of light vas advantageous, but the glare from direct sunlight on snow impeded visibility. Optinal light was sufficiently direct to show shadows in the tracks but diffuse enough to minimize contrast between areas shaded and those exposed. A partial overcast seemed to produce the best light condition. Factors influencing the activity of moose-- hence their observability-- are not well understood. If possible, the timing of counts should coincide with periods of greatest activity. Even when all the above requisites are met, some moose are overlooked because of heavy cover or other conditions difficult to appraise. Nevertheless, it is believed that the counts made in 1965 gave more accurate results than have been obtained in most other aerial census of moose.

The sampling plan *as initially designed consisted of 92 plots distributed somewhat uniformly over the island. Unusually inclement weather interfered with the flying schedule so that only 59 of these were counted. These, totaling 18.3 square miles or 8.6 percent of the island, yielded 76 moose. Extrapolated, this gave an estimated population of 848. Statistical analysis showed that, at the 95 percent confidence level, one could expect the actual population to be somewhere between 573 and 1123. This does not allow for animals missed through sampling inaccuracies. It probably is also subject to underestimation due to the fact that, among those 33 plots which could not be covered, average density was believed 
higher than that in the portion of the island which was sampled. Therefore, it appears that the 1965 Isle Royale winter moose population was conservatively somewhere between 850 and 1,000. It will be recalled that this was a winter when calves were below "normal" in number.

Whether this estimate signifies an increase of moose since Mech's work in 1960, can not be ascertained. Much of the difference could be attributed to the more intensive inventory method. On the other hand, a statistical error is involved in extrapolating from a limited number of plots. Efforts are now in progress to refine this census method further so that limits of variance in the estimate will not be so wide. Using the data from 1965 counts, a statistical approach is being developed by P. E. Dress, departmental statistician who will if necessary, employ a computer program to create the most efficient sampling design within specified limits of accuracy.

\section{Pathology}

A major objective in the moose studies has been to determine physiological and/or pathological conditions which may relate to predation vulnerability. This work has involved the exanination of many dead moose remains in addition to several collected for autopsy. We are indebted for assistance in the pathology work to members of the Purdue School of Veterinary Science and Medicine, in particular to S.M. Gaafer who has processed and exarnined much of the material. conditions being studied in detail include malnutrition as reflected by narrow fat depletion, occurrence of tapeworm cysts in the liver and lungs, lumpy jaw, and arthritis. Any of these may be instrumental in lowering the age at which moose become vulnerable to wolves.

Fat stores: Bone-marrow fat content probably is the best available index of general condition in the wolf-eaten moose. During winter 1965, marrow samples from several bones were preserved from each $\mathrm{kill}$ examined. These are to be analyzed for fat content to quantify the relationship between appearance and depletion. of all adult mocse killed during winter 1965, only one had markedly depleted marrow. This one, interestingly, was the three- or fouryear old male, an animal of an age at which vulnerability has been lowest. It would appear that some pathological condition was involved in the vulnerability of this animal.

Two moose were collected for autopsy during winter 1965. One was a cow which, though not involved in a wolf attack, gave valuable information on the age category of animals not regularly taken by wolves. This animal was estimated as around four or five years of age, and she was carrying one fetus. Fat stores were greater and pelage condition better than in any moose yet examined in winter. The other animal collected was an adult bull well past prime age. This animal had been wounded, apparently fatally, by wolves, Its visceral and body fat reserves were low, particularly as compared with the other autopsied animal; although its bone marrow was not severely depleted. 
Tapeworin cysts: Cysts or the lydatid tapeworn (Echinococcus granulosus) vere present in both of the autopsied noose; however, the level of parasitism was quite different for the two. The young cow showed but two cysts in the liver and one in the lungs. On the other hand, the old wounded bull had 74 cysts in the lungs and 24 on the surface of the liver. The lung cysts rangad up to 1.5 inches in diameter. A similarly heavy load, though not quite so great, was found by shelton in a moose which died after being injured by wolves. Any real appraisal of vulnerability due to cyst load will remain difficult or impossible, because the viscera are so seldom available for examination in moose taken by wolves. collecting adeguate numbers is both vulnerable and invulnerable classes of comparable ages in not ieasible.

Lumpy jaw: Deterioration of the jaw bone around inolar teeth, a condition generally referred to as lumpy jaw (or necrotic stomatitis), has been found in some older animals of this herd. It was reported by jech and by shelton during this study as well as by Murie for Isle Royale in 1929. There appears to be a close relationship between the impaction of woody food matter between teeth and adjacent bone and the initiation of necrosis. In some cases, however, a hole in the side of the faw appears to be the starting point. Necrosis apparently then proceeds down into the rnandible destroying bone around tooth roots until the marrow cavity is exposed. Remodeling of bone occurs, probably at the same time, and this eventually leads to an external swelling or the characteristic lumpiness. There may be extensive rarification of adjacent bone or abnormal wearing of teeth. In a few cases extensive decay of teeth was found.

It has appeared that this condition might result from infection with Actinomyces, though no report of isolation of this organism Erom moose has been found. It has presumably been found responsible for a similar condition in livestock. Fresh material showing several stages of the condition were obtained from winter kills in 1965 , and these were kept frozen. The specimens are now being studied by E. O. Haelterman of the School of Veterinary Science and Medicine at Purdue to determine the agent of this disease as well as to describe it.

A marked reduction in the incidence of lumpy jaw in 1963 and 1964 suggested that the condition was disappearing from Isle Royale. moose. However, four cases were found among kills in the winter of 1965. If a decline is in progress, more records will be required to demonstrate.it. The following table summarizes the occurrence of lumpy jaw in dead adult moose exanined during the winters 1959 through 1965. The incidence in carcasses examined at times other than winter is closely similar to this. 
Year Killed by Five or more !!olves liilled by less than

five lolves
Total, inclucing

Derths of unlonn $\mathrm{m} C \cdot$ use

\begin{tabular}{|c|c|c|c|c|c|c|c|c|c|}
\hline & $\begin{array}{l}\text { Advanced } \\
\text { Hecrosis } \\
\end{array}$ & $\begin{array}{r}\text { Incipient } \\
\text { Heciosis } \\
\end{array}$ & None & $\begin{array}{l}\text { Advanced } \\
\text { Necrosis }\end{array}$ & $\begin{array}{r}\text { Incinient } \\
\text { Nociosis } \\
\end{array}$ & None & $\begin{array}{l}\text { Advanced } \\
\text { Necrosis }\end{array}$ & $\begin{array}{r}\text { Incipient } \\
\text { Necrosis } \\
\end{array}$ & None \\
\hline 1959 & 0 & 0 & 7 & 1 & 0 & 0 & 1 & 0 & 7 \\
\hline 1960 & 1 & 0 & 5 & 1 & 0 & 1 & 2 & 1 & 6 \\
\hline 1961 & 1 & 3 & 5 & 1 & 2 & 3 & 2 & 5 & 8 \\
\hline 1962 & 1 & 4 & 5 & 0 & 1 & 1 & 1 & 6 & 9 \\
\hline 1963 & 0 & 3 & 9 & 0 & 0 & 1 & 0 & 3 & 11 \\
\hline 1964 & 0 & 0 & 10 & 0 & 0 & 1 & 0 & 0 & 13 \\
\hline 1965 & 1 & 4 & 6 & 0 & 0 & 1 & 1 & 4 & 7 \\
\hline Total & 4 & 24 & 4.7 & 3 & 3 & 8 & 7 & 19 & 61 \\
\hline
\end{tabular}

There seems to be some tendency for severe cases to be proport. tionally more frefuent in moose killed by smaller groups of wolves. This could imply a direct influence on vulnerability-- the more advanced pathology enabling fewer wolves to make a kill. However, on the average, more severe cases occur in older animals, and these may be more vulnerable for other reasons. Better determinations on these questions can be made when more accurate age determination becomes possible, especially in the older age classes of moose.

Arthritis: This condition, occurring with significant freguency, is another type of pathology which in all likelihood greatily $\because$ influences vulnerability. The finding of arthritis was described briefly in the 1964 report, and since then new cases have appeared. One of these was a cow killed by a pack of five on the ice of a small bay in February. In this animal there was no left acetabulun. the deep socket on which the thigh bone articulates with the pelvis. Degeneration and reshaping had left a completely flat surface in its place. Either an alternate articular structure had developed in soft tissues, or the hind limb of this animal was completely useless. Condition of the cow's bone marrow indicated that advanced malnutrition was not involved, so it is assumed the animal had been moving about satisfactorily to meet its forage needs. In any event, the ability of a moose so afflicted to run from or to defend itself against five wolves is much in question.

Since discovery of arthritis in this herd, efforts have been made to determine its incidence. In 29 adults found dead from natural causes and in which determinations could be made, 9 have shown sorne degree of this condition; the majority of these were advanced cases. In conjunction with G. M. Neher of the Purdue Veterinary School, this condition will be described, and Dr. Neher will attempt to determine what pathogen, if any, is involved. 
Miscellaneous parasites: Besides the specific objective of defining parameterg of vulnerability, general studies of parasites and diseases are underway. For example efforts were made this past winter to determine the presence of a lungworm, Pneumostrongylus tenuis, which has recently been reported as causing "moose disease". An examination for eggs of this worm: in moose feces collected from Isle Royale was carried out by P. D. Karns and his colleagues of the Minnesota Department of Conservation; further samples will be sent to them in the corning summer and fall. These men originally pointed out the ralationship between ioose disease and Pneumostrongylus in lininesota. First results indicate that the lungworm is not present in Isle Royale specimens. The symptoms of moose disease have never been reported from the island.

Studies of this past winter indicated an unusually low incidence of winter ticks. On two animals autopsied few ticks could be found, in contrast to other winters when specirnens examined were carrying hundreds or even thousands of ticks. Ordinarily in February and March the majority of moose show a rough pelage with extensive bare spots; these latter are presumed to have been rubbed in response to tick irritation. Of the many moose seen frorn the air and on the ground this past winter, a great majority showed smooth and undisturbed pelage.

During the summer of 1964, leeches were observed attached to the hind legs of moose feeding in ponds. Close observation was possible in several instances. It is suggested that leeches cause the heretofore unexplained open sores which are prevalent on hind legs of moose during summer. Such sores may be kept open by repeated imrnersion and by the feeding of an insect believed to be the moose fly. Haematobia alcis. This fly occurs in large swarms about each adult moose and has been observed concentrated on the sores. In september, an observation was made of a female redwinged blackbird walking about the back of a moose eating moose flies. This series of observations thus constituted a record of an interesting chain of animal interactions.

\section{Social behavior of Moose}

During the rutting season in fall 1963, a number of opportunities arose for close observation of breeding behavior. In 1964 such observations were not possible, mainly due to nearly continuous stormy weather. Between October 23 and 27, 1964, during a few days of fair weather, aerial herd composition counts were made. Of all cows classified at this time, 42 percent were in the company of bulls, and of all mature bulls, 56 percent were in the company of cows. In contrast, during the fall counts of 1963 which were flown on the same dates and in similar areas, the incidence of cow-bull associations was 23 percent for cows and 28 percent for bulls. This may reflect an extension of the rutting season in 1964, although rutting activity did not begin later than in 1963. Such extension may have occurred because the unusual amount of stormy weather interfered with or interrupted normal sequences of breeding behavior. It will be interesting to note whether a corresponding difference in time of calf drop can be detected in spring of 1965. 
Pellet-vegetation plots

A small sampling program has been initiated to study distribution and relative numbers of moose and hares and, at the same time, to study vegetation as it relates to these animals. To date 349 plots have been laid out on 25 lines located in widely separated parts of the island. These lines consist of from 10 to 20 plots spaced 200 feet apart. Each plot is marked with a 3-foot, heavy metal stake to insure some degree of permanence. Both stakes and spots. on adjacent trees are painted orange to facilitate rapid relocation.

Droppings of moose are counted and then cleared from the plots once a year (Fall) or, when convenient, twice a year (fall and spring). This is a standard method in big game work for measuring frequency of occurrence; it has been used previously for studying moose on Isle Royale by $L$. $W$. Krefting of the U. $-S$. Bureau of Sport Fisheries and wild life. It can in some circumstances be used to estimate animal numbers.

The pellet plot consists of a 15-foot radius circle 10.162 acres) around the stake. A pellet group, that is, all the pellets dropped in one defecation, is considered one unit. Then scattered groups are only partially within the plot, the estinated fraction is recorded. Feces of moose in suinmer are usually amorphous as contrasted to the pellet-form dropped at other seasons; thus it is possible to distinguish the season of an area's usage. In order to estimate population numbers from these counts, defecation rates inust be determined. Efforts to accomplish this by winter tracking during known periods are now in progress, but adequate information has not yet been obtained.

Hare pellets are counted individually and then cleared from within a 2.5-foot-radius circle around each stake. No attempt will be made at present to extrapolate these counts into population estimates. If the plots are checked annually over a number of years, then presumably fluctations in the numbers of hares can be determined, and such in turn could be compared for synchrony with mainland populations.

A description of vegetation is being made within a 15-foot radius at each plot. All measurements are by visual estimate: hence figures are not precise. Data are recorded for all woody species and for the most common herbaceous species, the remainder being lumped into broader categories. Plants are recorded according to height classes being designated as greater than $1,2,6,10$, 15, and 35 feet above the ground. Species abundance is indicated according to estimated ground-area intercept. The main purpose of these descriptions is to provide an index of types and quantities of forage available.

Intensity of usage, if any is recorded subjectively as sonewhere between very light and very heavy. Where the season in which foraging took place is evident, this is recorded, and distinction is made between inoose and hare usage. plants with a third or more of the crown branches dead are listed as decadent, and recently-dead plants are so recorded. Trees blown down recently are recorded with notation as to whether they were alive or dead at the time of falling. 
These plot lines for pellet counts and vegetation analysis are being established with a long-term outlook. Initial readings contribute relatively little to present studies, but it appears likely that the work can be kept up as part of the routine park research program or otherwise.

In this light, the system can provide information on major population trends and shift of moose and hares. It can likewise furnish an index of vegetation use by these browsers and an insight into successional trends which will strongly influence food availability in the future. Such information will be needed in the management decisions of years to come.

Predatory Habits, Population Dynamics, and Social Behavior of Wolves

In the present three-year phase of the Isle Royale research program, primary concern is with the moose herd. However, as a logical part of this objective, information on the wolves continues to be accumulated. The wolves have a vital role as predators, and their status is pertinent in the ecology of the moose. Every effort is being made to obtain information on numbers and reproductive success as well as on the hunting habits of the wolves. Beyond this, however, our study circumstances afford original observations on social behavior.

Wolf numbers and structure of the packs

Though it is possible to estimate rather closely the number of wolves on Isle Royale, it can never be determined if and when all are accounted for. There appeared to be an increase from winter 1964 to winter 1965. A minimum count of 25, the largest recorded during the years of this study, was made on February 27, 1965. It is believed that the actual population exceeded this by at least three. Data froii winter 1964. led to a ininimum estimate of 25 (26, incluaing one known to have died in February). Circurnstances for counting during 1965 were less favorable, because flying weather and tracking conditions were poorer, and the structure of wolf groups was less stable.

In 1964 the large pack nurnbered consistently 20, after an initial count of 22 on February 2. In 1965, a maximum of 18 was seen on several occasions; one individual was often trailing or widely separated. Evidence acquired in early February indicated that actually two loosely-associated individuals might be present, giving a possible total of 19 for the large pack. Though the pack was 18 as seen most of the time, the picture was actualiy more complicated. On February 24, two wolves considered to be independent were feeding on a kill about a mile from the big group. These two, in response to howling, came toward and either joined with or passed through the ranks of the large pack. The next opportunity for a good count was on February 27 when 20 wolves were seen in the same vicinity in groups of $3,13,1$, and 3 . From the circumstance, it appeared that a reorganization of the previous groupings, 18 and 2, had occurred. If so, then the large pack 
inight have as rnany as 20 or even 21 individual wolves associated with it at one time or another. Another possibility is that the groupings seen on the $27 \mathrm{th}$ included some animalssnot previously accounted for.

Locating and distinguishing minor groups was especially difficult in 1965 because of weather interruptions and unfavorable tracking conditions. On a basis of sign, at the time 20 wolves were accounted for as above, it was estimated that as many as three additional aninals inight be present in the same vicinity.

Of most significant interest was the discovery of a new pack of Eive confined to the northeast sector during our observations and apparently separate from other groups. This brings the ininimum total to 25 for the island, but leads to a nore realistic estimate of 28.

Most sightings of single wolves were either close to the large pack or in areas recently traversed by thein. Only one observation of a single was made elsewhere. Besides the two observed repeatedly near the large pack, four more sightings of pairs were made. These were all in the central region of the island, but probably not the same animals in all sases.

wolf population dynamics

In the early years of this study there was little or no evidence of reproduction and turnover in these wolves, and a relatively stable condition was assumed to exist. More recently, there has been convincing evidence of recruitinent and loss. Increases were observed in the total wolf population in both 1964 and 1965. Partial remains of an adult were found in March 1964. There was no evidence how this animal died but the teeth indicated it was advanced in years.

In July 1964, tracks of pups were discovered at Feldtmann Lake by Erik Stauber, and shortly thereafter we discovered at the same site a dead wolf pup approximately three nonths of age. Examination revealed the animal to have been extremely emaciated, and death could have been due to starvation. During the same period, some 9 miles away. D. R. Kangas of the Park Service and others, while listening to wolves howl, believed that yips of pups could be distinguished. Although such distinction is difficult, MF. Kangas has had the experience of hearing wolves on a number of occasions.

On October 24, 1964, while making moose herd composition counts from the air, pilot Bill Nartila and $I$ saw a pack of 15 wolves near Lake Halloran. Both He and I agreed that there were three pups in this group. Then, during winter 1965, repeated observations were made of four pups in the large pack, and the pack of five contained one. My ability to recognize pups had been aided by suggestions from two University of Chicago animal behaviorists, Benson Ginsburg and Jerome Woolpy, who are studying captive wolves. Unfortinat:iy, our discussions with them were held after the winter 1964 observations had been nade. 
In years prior to 1964 only one pup had been described; this a member of the large pack in winter 1962. In 1964 we believed that certain of the large pack were pups. This was somewhat anticipated since the pack had increased by as many as five from the previous winter. However, we did not have confidence in our ability to make this distinction and did not reach a positive conclusion concerning the presence of pups.

Breeding, which occurs in mid-February, has been noted in all years during which the large pack could be kept under regular, close surveillance. In 1964 the dominant or "alpha" male and one other were, at one time or another, observed in persistent breeding efforts. There was some interference by the alpha male with the breeding efforts of the others. The same approximate pattern was repeated in 1965. In the new pack of five, copulation resulting in coupling was observed on one occasion.

The 1964-65 observations indicate that at least three litters may have been born in spring 1964. This involves two assumptions: first, that the one pup with the pack of five was the survivor of a litter probably born at the northeast end of the island, and secondly, that David Kangas did hear a pup or pups at a locale 9 miles from where a litter was known to be. Also indicating the presence of three litters is the evidence that among the four pups in the large pack, there was a tendency to split three and one. One appeared smaller, but it was not determined whether it was the single when the pups were split. Thus, the four may have come fron two litters, in addition to that of the five-pack.

It is reasonable to suppose that the early progeny of wolves which immigrated to Isle Royale in 1949 survived in such numbers that they soon populated the island to capacity. In subsequent years, reproductive success may well have been nil. However, after fourteen or so years this generation would be dying out, and replacements could be coming on rapidly. In the absence of more precise information, the pattern of population turnover must remain speculative.

The finding of a supposedly starved pup, plus the regular observation of breeding activity, does suggest that failure of pups to survive rather than failure of adults to breed is the principal factor in population stability. This is suggested even though we observe the alpha male interfering with the breeding of others; actually, he himself could be responsible for a number of pups each year. The increase in wolf rumbers may possibly be related to an increase in available food. The higher figures of the recent moose census may indicate a real increase which could have provided spring and summer food adequate to allow a degree of success in raising of pups not previously possible. Even were the moose population not greater, if its reproductive rate had increased, then there should be more food available to the wolves. It is suggestive to associate the large calf crop of 1964, showing heavy losses during the early months, with the survival of five wolf pups into the following winter. 
Rate and distribution of kills

In a 44-day observation period the large pack, or parts thereof, killed at least 11 and probably 12 moose. One of these was a calf, and two more may have been. An adult bull was shot for autopsy after it had been wounded so severely that there can be little question of its soon falling to the wolves. One moose seen dead but not examined had not been fed upon; however the large pack had been active in the vicinity and may have injured it. Between February 7 and 11 the wolves were not seen feeding; yet on the latter date they were observed defecating heavily. This strongly indicates that a moose had been devoured within the previous couple of days. They probably killed and $\overline{x i n i s h e d ~ u p ~ a ~ m o o s e, ~}$ possibly a calf, while we were grounded. In the calculations which follow, it was assumed that a calf was eaten.

To determine whether rates of consumption by wolves varied between 1964 and 1965, calculations were made to estimate the average poundage of moose eaten per wolf per day. Weights of moose are based in part on figures used by Nech. Because unconsumed parts are believed greater than his estimates, net edible weights (pounds) which follow are 10 to 15 percent lower than those used by Mech: calves, 250; yearlings, 550; nature cows and young bulls, 700; and mature bulls, 850. Consumption rates were found to average nearly the same between the two years: 10.5 pounds in 1964 and 10.6 in 1965 .

In 1964 the pack of 20 made a kill on the average of once every 2.9 days, while in 1965, with 17 or 18 animals, the rate was every 3.5 days. Such a comparison can not be made with precision because of occasional splitting up in 1965. There was less variance in the frequency of kills in 1964 when the longest period between kills was six days. In 1965 the longest interval was 9 or ten days. Distances traveled between kills in 1964 averaged 19.6 miles with a maximum of 45 , while in 1965, as best it could be figured, the average was 22.4 with a maximum of 79 miles.

As has been the case in past years, less is known of the predation rate for the smaller groups of wolves. The pack of five was discovered at the carcass of an adult half eaten on February 22, and they left this kill 9 days later. Eleven days after that, the remains of another kill, age as yet unknown, were discovered nearby. Presumably the five had made and finished this kill during the interval. If, in the future, this group remains intact and separate from the large pack, and if flying conditions are more favorable than in 1965, information comparable to that secured on the large pack may be forthconing. 
Ranqes of the packs

The area occupied by the large pack or parts thereof in 1965 closely coincided with that of the year before. Ice conditions in 1965, being more typical of past years than in 1964, permitted access to outer islands and shortened routes across bays. The distribution of kills varied between 1964 and 1965 as it has ariong all previous year. In the former year the bulk of mid-winter kilis occurred along the southern shore of the southwest end of the island, including the southwest end of Siskiwit Bay. In 1965 the greatest number occurred in the Malone Bay-siskiwit Lake region.

It would be interesting to know whether certain areas in which many kills are made one winter are found by the wolves to be less productive in the years immediately following. In 1965 there was no lack of moose in the region of heavy killing the previous year. on the other hand, there could easily have been a qualitative change in the animals using these sites, thus accounting for any difference in hunting success.

The "new" pack of five appears to be exploiting a region which has not been hunted in mid-winter by the large pack since 1960. However, small groups have been seen there regularly. In early March the tracks of five or more wolves were seen on Lake Richie. This is an area lying half way between the known range of the pack of five and the northeastern boundary of the large pack's range. The wolves in question could have been the fivepack or a subgroup of the large pack.

Other small groups and single wolves tended, as in 1964, to range within the central sector of the island. The proximity of some of these to the large pack was discussed above.

Social behavior in wolves

A noteworthy change in behavior occurred within the big pack between 1964 and 1965, and this may lead to significant changes in its stability and leadership. In 1964, members of the big pack all participated extensively in greeting gestures, play, and harassment of subordinate individuals. In contrast there was very little of such socializing observed in 1965, even though four pups were known to be present. Also in 1964, during February and March, the pack of 20 remained consistently intact. In the same period of 1965, the 18 were separated into subgroups several times. Once a group of 11 traveled $35 \mathrm{miles}$ and were apart from the others for seven days. During that period, cone session of widespread play. greeting, and harrassment was observed among the 11 .

Corresponding to these differences were differences in the behavior of the dominant or alpha male. This large wolf, recognizable individually from the air, assumed his role in the complete sense during 1964. However, in 1965, he lagged behind, did not inix with the others as much, and in general did not assert himself nearly so much as before. Yet he would still have to be classified as the most dominant of the group. During the several instances of splitting up, he was with, or accompanied by, only one or two others; the instance of socializing among the subgroup of 11 may have been associated with his absence. 
One interpretation of these observations is that the alpha male is aging and -losing the enthusiasm or energy necessary to assert himself as before. The pack, in turn, is reacting to this change with uncertainty and insecurity: its social well-being has been disturbed. If such is true, it has not affected the pack's ability or willingness to hunt or to kill moose. We may be witnessing a transition to new leadership or to new structure. The appearance of the five-pack may have been one result already. This is probably a fanily group which separated recently from the large pack. If extent of general play is an index of social wellbeing, then the five-pack by all appearances is a well adjusted group.

\section{Studies in Prospect For 1965-66}

During the coning year most of the work described here will be continued. As stated, plots will be counted as before and, if feasible, a few nore inay be added. Special efforts will be made'. to get estimates of natality and survival and to further inprove the census program. During the coming surmer, the primary objective of our undergraduate assistants will be to investigate areas in which wolves may be denning, thus pursuing the discoveries made last surner. Toward the end of the coming report period, much time will be devoted to final reports and publications. 